Research Article

\title{
Application of Composite Deflecting Model in Horizontal Well Drilling
}

\author{
Shaohu Liu ${ }^{1}$ and Zhichao Zhu ${ }^{1,2}$ \\ ${ }^{1}$ School of Mechanical Engineering, Yangtze University, Jingzhou 434023, China \\ ${ }^{2}$ College of Mechanical and Vehicle Engineering, Hunan University, Changsha 410082, China \\ Correspondence should be addressed to Shaohu Liu; liushaoh@126.com
}

Received 23 October 2019; Accepted 11 February 2020; Published 9 March 2020

Academic Editor: Stefan Balint

Copyright (c) 2020 Shaohu Liu and Zhichao Zhu. This is an open access article distributed under the Creative Commons Attribution License, which permits unrestricted use, distribution, and reproduction in any medium, provided the original work is properly cited.

\begin{abstract}
Based on current issues of difficulties in controlling horizontal well trajectory and high cost in drilling deflecting, a compound deflecting BHA (bottom hole assembly) with diameter-adjustable stabilizer (DAS) and bending-adjustable housing (BAH) is presented. According to the DAS operational principles and the stress condition in operation, the computational formula of wedge's axial moving displacement and piston's radial telescopic displacement of the DAS driven by drilling fluid pressure is presented. This formula is verified by lab experimental simulation. Three-points-circle method is utilized to calculate geometrical build up rate of compound deflecting BHA, and the result is verified by field data. The method is utilized to make design and calculate for compound BHA. The research can be used as a reference for compound deflecting drilling in horizontal wells. The flow rate and pressure difference have a very serious impact on the flow regulator erosion, so the flow rate and pressure difference should be controlled when the DAS works, and it is suggested that the flow regulator should maintain and replace frequently when in service.
\end{abstract}

\section{Introduction}

With the large-scale development of unconventional oil and gas (shale gas and tight oil), American horizontal drilling operation increases much, which started to exceed that of vertical drilling after 2010 for drilling footage. The American horizontal well rapidly increased from 1144 wells in 2000 to 17,721 wells in 2012, and the proportion in all wells rose from $3.68 \%$ in 2000 to $36.65 \%$ in 2012 , namely, more than $1 /$ 3 of American new wells were horizontal in 2012. It is expected that American horizontal wells will approach 22,000 in 2017 , accounting for over $40 \%$ of all wells. With the largescale development of unconventional oil and gas, American horizontal wells' drilling footage will rise stably to as high as $70 \%$ in proportion in 2018 expectedly [1-3].

This indicates that the horizontal drilling technology has been widely applied. Horizontal drilling process is mainly divided into prespudding engineering, drilling engineering, completion engineering, postdrilling treatment, oil test, and fracturing. The drilling engineering consists of 1st vertical section, 2nd vertical section, 2nd deviated section, and 3rd horizontal section. According to the average data from 3 horizontal wells of a gas field of Sinopec in China, the average total investment for a well is 24.3 million RMB. The drilling engineering investment is 13.25 million RMB, accounting for $54.5 \%$ of the total; the drilling cost of $2 \mathrm{nd}$ deviated section is 5.6933 million RMB, accounting for $23.4 \%$ of the total $[4,5]$.

In horizontal drilling, the 2 nd deviated section drilling technology and drilling cost is one of the main problems hindering large-scale application of horizontal wells. In the 2nd deviated section drilling process, in order to control well trajectory and prevent from deviation, a rotary steering drilling tool is usually used. Sometimes multiple fixed stabilizer BHA or combination of DAS and motor are used. As shown in Figure 1, the DAS diameter change is controlled by adjusting the drilling fluid pressure on the ground, and the deviation is achieved by changing the diameter. However, 


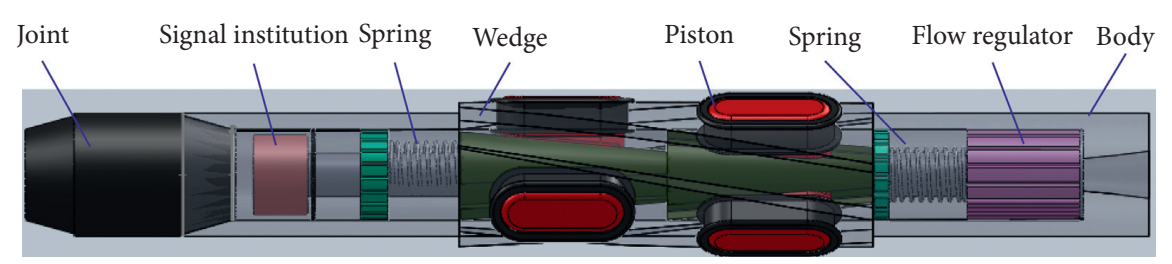

Figure 1: Structural diagram of DAS.

the cost of the rotary steering drilling tool is very expensive, multiple fixed stabilizer BHA needs frequent replacement of stabilizer, and continual pulling out and tripping in caused issues of high cost and labor intensity. In contrast, the combination of DAS and motor with $\mathrm{BAH}$ is able to achieve deviation prevention, fast drilling, effective control of well trajectory, and low drilling cost [6]. As shown in Figure 2, $\mathrm{BAH}$ is integrated with the motor, and the bending angle of $\mathrm{BAH}$ can be adjusted to achieve deviation. During the drilling process, DAS and BAH combine to achieve composite deviation. How to use the combination of DAS and motor with BAH to accurately control well trajectory remains to be solved.

The working principle of variable diameter stabilizer and its function in directional drilling were introduced $[7,8]$. The variable diameter stabilizer was designed, and its working mechanics were calculated $[9,10]$. The variable diameter stabilizer was developed and applied in the field $[11,12]$. In order to make the variable diameter stabilizer play a better role in the directional well, the variable diameter stabilizer was used in combination with the positive displacement motor, antiwear and antitorque tool [13-15]. However, the compound deflection of variable diameter stabilizer and $\mathrm{BAH}$ is seldom applied in the field, and the mechanism and model of the compound deflection are seldom studied in the application process. Therefore, it is necessary to carry out the research on the compound deflection model of DAS and motor with BAH.

\section{Compound Deflecting BHA}

2.1. Introduction of DAS and BAH. As shown in Figure 1, DAS is mainly composed of body, flow regulator, spring, piston, wedge, signal institution, and joint. During drilling, the tool is controlled by the pressure difference generated by the drilling fluid. When the displacement of the mud pump increases, the drilling fluid actuates the flow regulator due to pressure difference. Under the effect of pressure difference, the wedge starts to move axial downward, pushing the piston radial out, and the spring is compressed. When the displacement of the mud pump decreases, the pressure difference generated by the flow regulator starts to decrease. The spring starts to rebound and push the wedge to start the axial upward movement, while the piston radial retracts back to the starting position. The deviation is achieved by the piston radial displacement.

As shown in Figure 2, BAH is mainly composed of a lower shell, curved axle, adjusting ring, and upper shell. Deflection angle can be obtained from $0^{\circ}$ to $3^{\circ}$ by adjusting

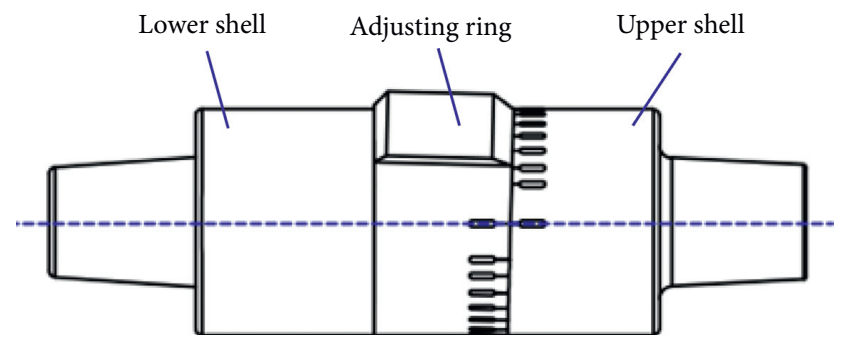

FIgURE 2: Structural diagram of BAH.

the matching relationship between the shell (lower shell and upper shell) and curved axle.

2.2. Conventional BHA with DAS. DAS is able to change the diameter in well. Therefore, the combination of the DAS and motor can effectively control well trajectory and reduce pulling out and tripping in arising from diameter problems of the fixed stabilizer. Drilling practice shows that ROP increases about $24 \%$ if the combination of the DAS and motor is used. Rotary BHA is shown in Figure 3(a): bit + near bit fixed stabilizer + straight motor + DAS + drill collar + drill pipe. Steering power BHA is shown in Figure 3(b): bit + near bit fixed stabilizer + fixed bending housing motor + DAS + drill collar + drill pipe $[8,16]$.

2.3. Compound Deflecting BHA with DAS. Motor with fixed-angle bending housing can only satisfy the demand of a fixed build up rate. It increases not only the quantity of tools but also operational cost. The multistage BAH can adjust the housing angle repeatedly in the well [17-19]. The combination of multistage $\mathrm{BAH}$ and DAS can make the BHA achieve compound deflecting. The current computational method considers the gap between the fixed stabilizer and the wall. Therefore, a new computational method is needed to calculate the build up rate of the compound deflecting tool in horizontal drilling. As shown in Figure 4, the compound deflecting BHA is bit + near bit fixed stabilizer + motor with $\mathrm{BAH}+\mathrm{DAS}+$ drill collar + drill pipe.

\section{Diameter Adjustment Mechanical Analysis of DAS}

3.1. Piston Movement Mechanical Analysis of DAS. The simplified structure is shown in Figure 5. In the drilling process, the pressure difference from the bottom of the borehole applies on the flow regulator and makes it to move. The driving force $F_{P}$ of drilling fluid will apply to 6 pistons via wedges $[9,10]$. 


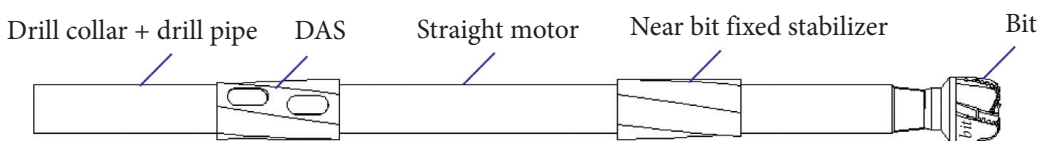

(a)

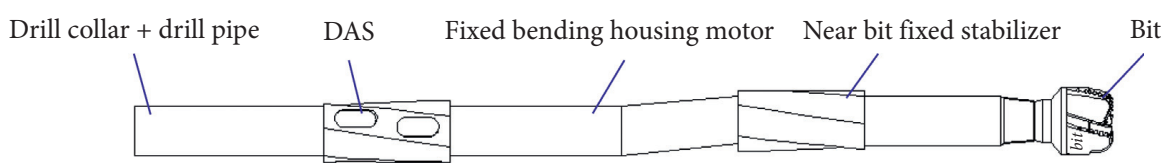

(b)

Figure 3: Conventional BHA with DAS.

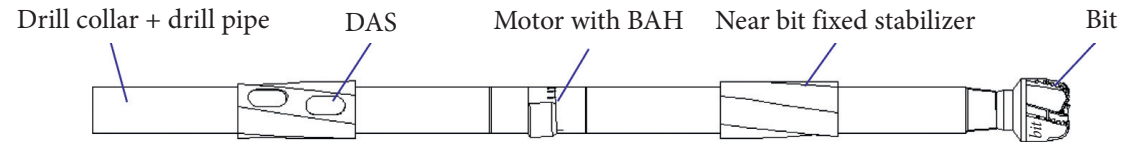

Figure 4: Compound deflecting BHA with DAS.

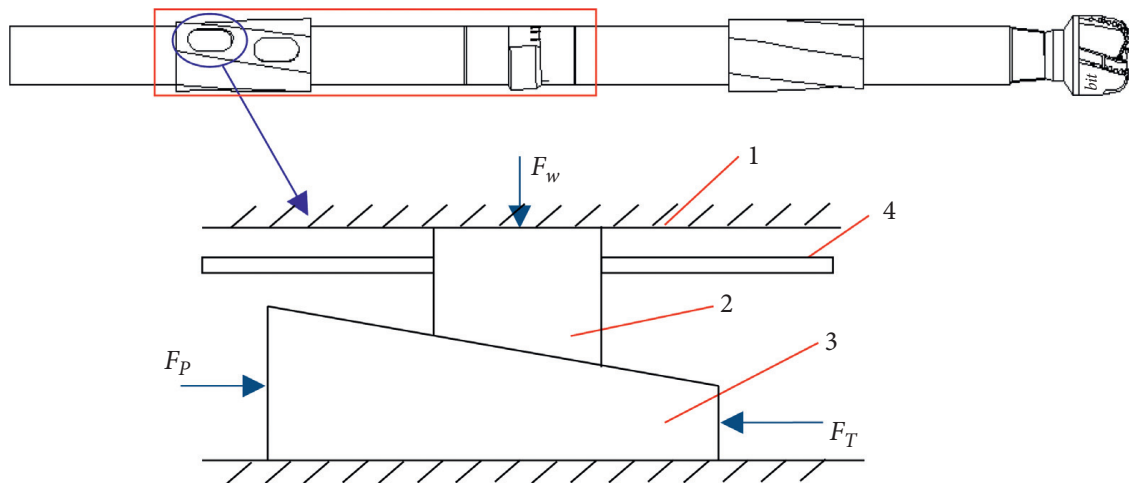

FIGURE 5: Stress condition of telescopic combination (piston and wedge). 1: well wall, 2: piston, 3: wedge, and 4: body.

As Figure 1 depicts, the flow regulator gets the driving force $F_{P}$ from drilling fluid:

$$
F_{P}=\Delta P S,
$$

where $\Delta P$ is pressure difference, $\mathrm{MPa}$ and $S$ is throttling area of the flow regulator, $\mathrm{m}^{2}$.

Restoring force $F_{T}$ of the spring is

$$
F_{T}=k \Delta l \text {, }
$$

where $k$ is stiffness of spring, $k=92 \mathrm{~N} / \mathrm{mm}$ and $\Delta l$ is length of spring compression, $\mathrm{m}$.

The telescopic combination mainly suffers driving the force of drilling fluid and restoring the force of the spring and the force of the wall $[9,20,21]$. Respectively, setting the piston and the wedge as the object of study, static analysis was made on the telescopic combination. The stress condition is shown in Figure 6.

When the piston contacts the wall of the well, the static equilibrium equation is

$$
\left\{\begin{array}{l}
F_{N 2}-F_{N}-F_{f 2} \cos \alpha-F_{N_{1}} \sin \alpha=0, \\
F_{N_{1}} \cos \alpha+F_{f 2} \sin \alpha-F_{W}-F_{f 1}=0,
\end{array}\right.
$$

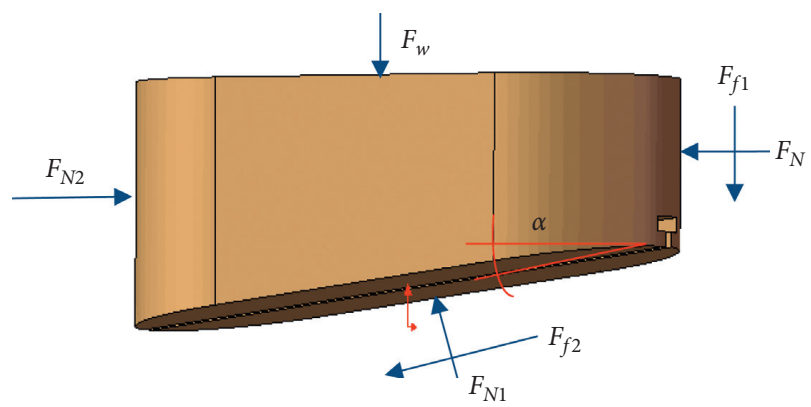

FIgURE 6: Stress condition of the piston.

where $F_{N}$ is the normal pressure of the hole in the housing to the piston, $\mathrm{N} ; F_{f 1}$ is the friction force between the piston and the hole, $\mathrm{N} ; F_{f 2}$ is the friction force between the piston and the wedge, $\mathrm{N} ; F_{N 1}$ is the normal pressure of the wedge to the piston, $\mathrm{N} ; \alpha$ is the dip angle of the piston slope, ${ }^{\circ}$. Besides,

$$
\begin{aligned}
& F_{f 1}=f_{1}\left(F_{N}+F_{N 2}\right), \\
& F_{f 2}=f_{2} F_{N_{1}},
\end{aligned}
$$

where $f_{1}$ is the static friction coefficient between the piston and the hole in the housing, dimensionless; $f_{2}$ is the static 
friction coefficient between the piston and the wedge, dimensionless. The stress condition of the wedge is shown in Figure 7.

The equilibrium equation of the wedge is

$$
\left\{\begin{array}{l}
F_{P}-F_{T}+F_{f 2} \cos \alpha+F_{N 1} \sin \alpha=0 \\
F_{N_{1}} \cos \alpha-F_{f 2} \sin \alpha=0
\end{array}\right.
$$

During the downward movement of the wedge, the piston is pushed out simultaneously and the diameter of the tool increases until it reaches the wall. The equation between the pressure difference $\Delta P$ and guiding body moving displacement $\Delta l$ is

$$
\Delta l=\frac{\pi\left(D_{1}^{2}-D_{2}^{2}\right)}{4 k} \Delta P .
$$

Substituting $D_{1}=97 \mathrm{~mm}, D_{2}=45 \mathrm{~mm}$, and $k=92 \mathrm{~N} / \mathrm{mm}$ into equation (7),

$$
\Delta l=63 \Delta P .
$$

Hence, the equation between moving displacement $\Delta l$ and diameter $D$ of the tool when the piston is pushed out is

$$
D=200+2 \Delta l \tan \alpha,
$$

where $\alpha=6^{\circ}$ and $\alpha=7^{\circ}$, and the result is shown in Figure 8 .

3.2. Experimental Study. The experimental simulation was made to study the relation between the guiding body moving displacement and tool diameter change of the DAS when the pressure difference was applied. The experimental devices were DAS, electric push rod, and related accessories; core length measurement apparatus; and so forth, as shown in Figure 9 [9]. In order to meet the need in the experiment, the DAS is printed on a $3 \mathrm{D}$ printer using polymer material. By coding the attached encoder, the electric push rod moving displacement can be controlled, and thus the guiding body moving displacement can be controlled. Meanwhile, the diameter of the tool in every displacement was measured by the core length measurement apparatus. The result is shown in Table 1.

\section{Geometric Build-Up Rate Computation of the Curved Section in Horizontal Wells}

4.1. Geometric Build-Up Rate Computation of Compound Deflecting BHA. Karisson et al. presented the geometric build-up rate computational method of the steering tool with bending housing in 1985 [22]. In 1990, Hassen et al. presented the biradius method to compute the build-up rate of bending housing [23]. In recent years, Liu et al. improved the geometric build-up rate computational method of deflecting BHA based on the three-points-circle method $[24,25]$. Afterwards, the method attracted considerable attention and got widely applied [26, 27]. Based on the threepoints-circle method, the effect of the diameter change of DAS and bending change of BAH on the geometric build-up rate of compound deflecting $\mathrm{BHA}$ was comprehensively

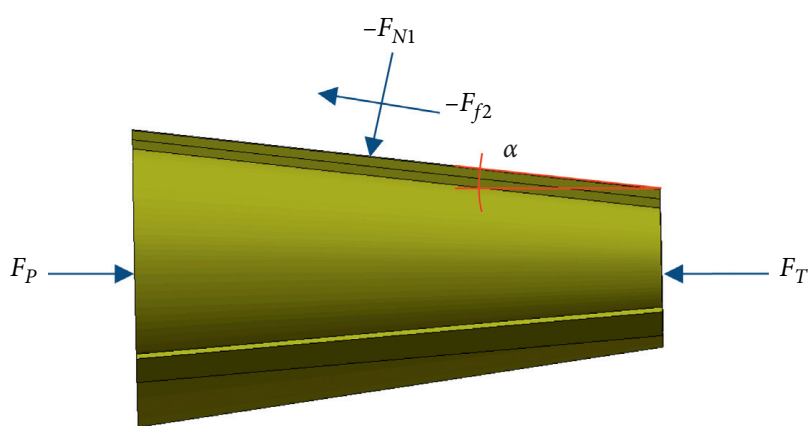

Figure 7: Stress condition of the wedge.

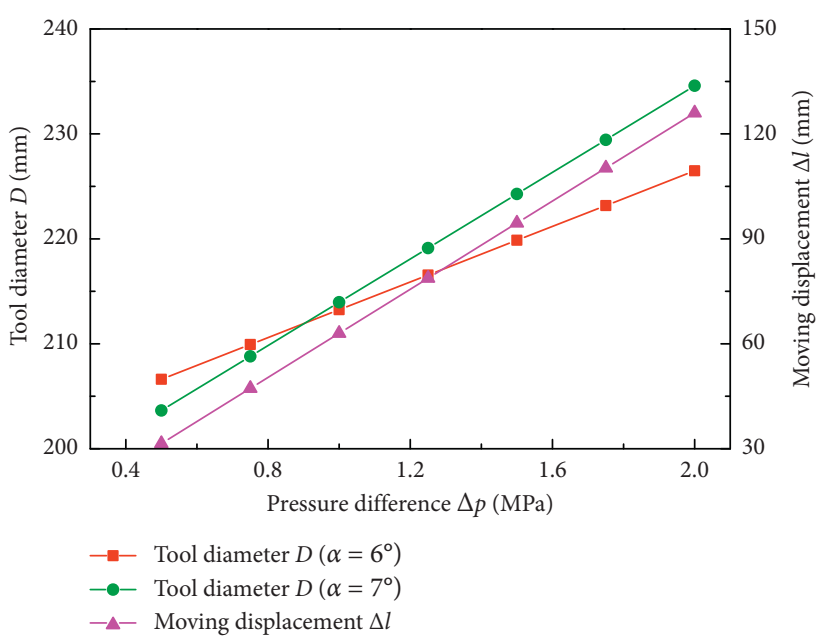

FIGURE 8: Relation among pressure difference, moving displacement of the wedge, and diameter of the tool.

considered. Figure 10 shows a compound deflecting BHA: bit + near bit fixed stabilizer + motor with $\mathrm{BAH}+\mathrm{DAS}+$ drill collar + drill pipe.

For compound deflecting BHA, the coordinate parameters are

$$
\left\{\begin{array}{l}
y_{2}=L_{1}, \\
x_{3}=L_{3} \sin \gamma, \\
y_{3}=L_{1}+L_{2}+L_{3} \cos \gamma,
\end{array}\right.
$$

where $L_{1}$ is the distance between near bit fixed stabilizer and bit, $\mathrm{m} ; L_{2}$ is the distance between near bit fixed stabilizer and motor with $\mathrm{BAH}, \mathrm{m} ; L_{3}$ is the distance between motor with $\mathrm{BAH}$ and DAS, $\mathrm{m}$; and $\gamma$ is the angle of BAH $\left({ }^{\circ}\right)$.

The telescopic distance $\delta$ of piston of DAS has a great effect on the build-up rate of compound deflecting BHA. Assuming that the wall touches the lower stabilizer, the DAS coordinates can be described as

$$
\left\{\begin{array}{l}
x_{3, \delta}=x_{3}+\Delta x \\
y_{3, \delta}=y_{3}+\Delta y
\end{array}\right.
$$

where $\Delta x=\left(L / L_{1}\right) \delta \cos \beta$ and $\Delta y=-\left(L / L_{1}\right) \delta \sin \beta ; \quad x_{3, \delta}$ and $y_{3, \delta}$ are the DAS coordinates with the build-up rate affected by the piston's telescopic movement, $\mathrm{m}$; and $L$ and $\beta$ are intermediate variables. 


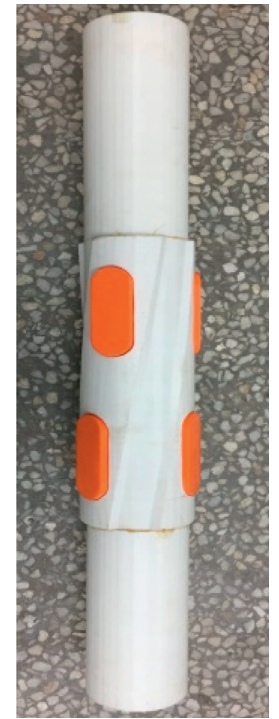

(a)

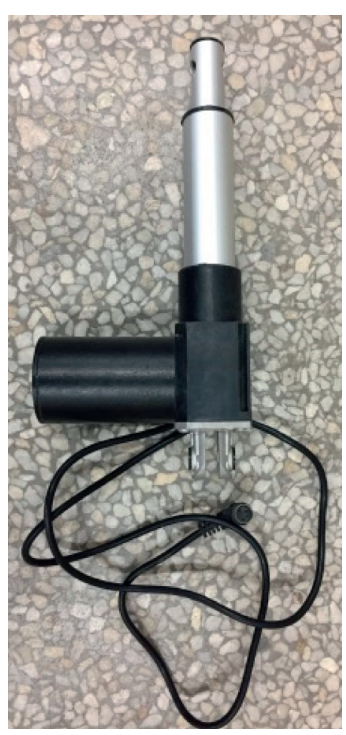

(b)

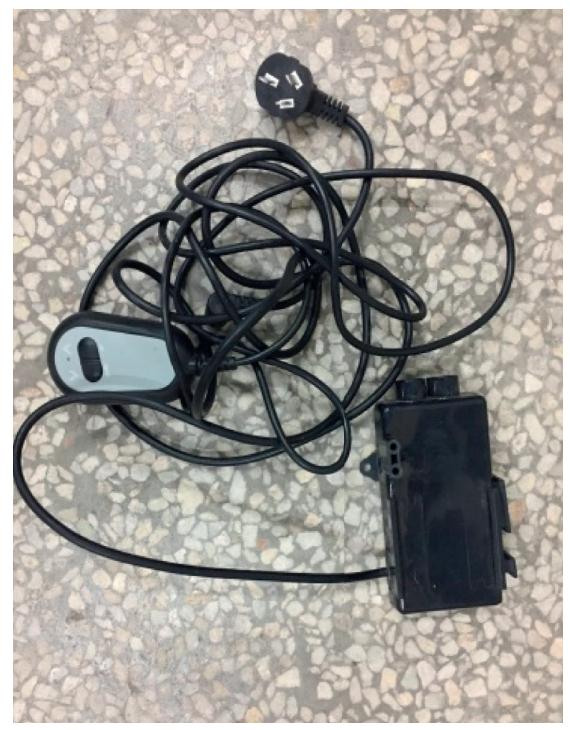

(c)

Figure 9: Partial experimental equipment. (a) DAS. (b) Electric push rod. (c) Controller.

For single bending compound deflecting BHA,

$$
\left\{\begin{array}{l}
\tan \beta=\frac{L_{3} \sin \gamma}{L_{1}+L_{2}+L_{3} \cos \gamma}, \\
L=\left(L_{1}+L_{2}\right) \cos \beta+L_{3} \cos (\beta-\gamma) .
\end{array}\right.
$$

The formulas above can be simplified as follows due to the small angle of housing bending:

$$
k=k_{\gamma}+k_{\delta}
$$

where $k_{\gamma}$ is the geometric build-up rate of compound $\mathrm{BHA}$, $\left({ }^{\circ}\right) / 30 \mathrm{~m} ; k_{\delta}$ is the build-up rate due to the piston's telescopic movement of DAS, $k_{\delta}=\left(10.8 \delta / \pi L_{s} L_{1}\right),\left({ }^{\circ}\right) / 30 \mathrm{~m}$; and $L_{s}$ is the length of the stabilizer, $m$.

Therefore, the build-up rate formula of compound deflecting BHA with single bending is

$$
k=\frac{60}{L_{T}} \lambda \gamma,
$$

where $L_{s}=L_{2}+L_{3}, L_{T}=L_{1}+L_{s}$, and $\lambda=L_{3} / L_{s}$.

4.2. Field Test Verification. The example took the horizontal well data of H10-3 from field CN. The BHA was $\Phi 215.9 \mathrm{~mm}$ $\mathrm{T} 1655 \mathrm{~B}+\Phi 172 \mathrm{~mm}$ motor $\left(1.25^{\circ}\right) \times 6.46 \mathrm{~m}+$ check valve + $(411 \times 4 \mathrm{~A} 10)+\Phi 158.8 \mathrm{~mm}$ nonmagnetic drill collar $\times$ $8.95 \mathrm{~m}+$ directional joint $+\Phi 158.8 \mathrm{~mm}$ drill collar $\times$ $26.92 \mathrm{~m}+(4 \mathrm{~A} 11 \times 410)+\Phi 127 \mathrm{~mm}$ heavy-weight drill pipe $\times 139.6 \mathrm{~m}+\Phi 127 \mathrm{~mm}$ drill pipe $\times 749.56 \mathrm{~m}$ $+(411 \times 520)+\Phi 139.7 \mathrm{~mm}$ drill pipe + top drive. Basic parameters were $L_{1}=1.81 \mathrm{~m}, L_{2}=1.0 \mathrm{~m}, L_{3}=6.46 \mathrm{~m}$, and $\gamma=1.25^{\circ}$. 
TABLE 1: Experimental simulation of the guiding body moving displacement and telescopic diameter.

\begin{tabular}{lc}
\hline $\begin{array}{l}\text { Guiding body moving displacement } \\
(\mathrm{mm})\end{array}$ & Telescopic diameter $(\mathrm{mm})$ \\
\hline 10 & 101.5 \\
20 & 103 \\
30 & 104.5 \\
40 & 105.8 \\
50 & 107 \\
60 & 108 \\
\hline
\end{tabular}

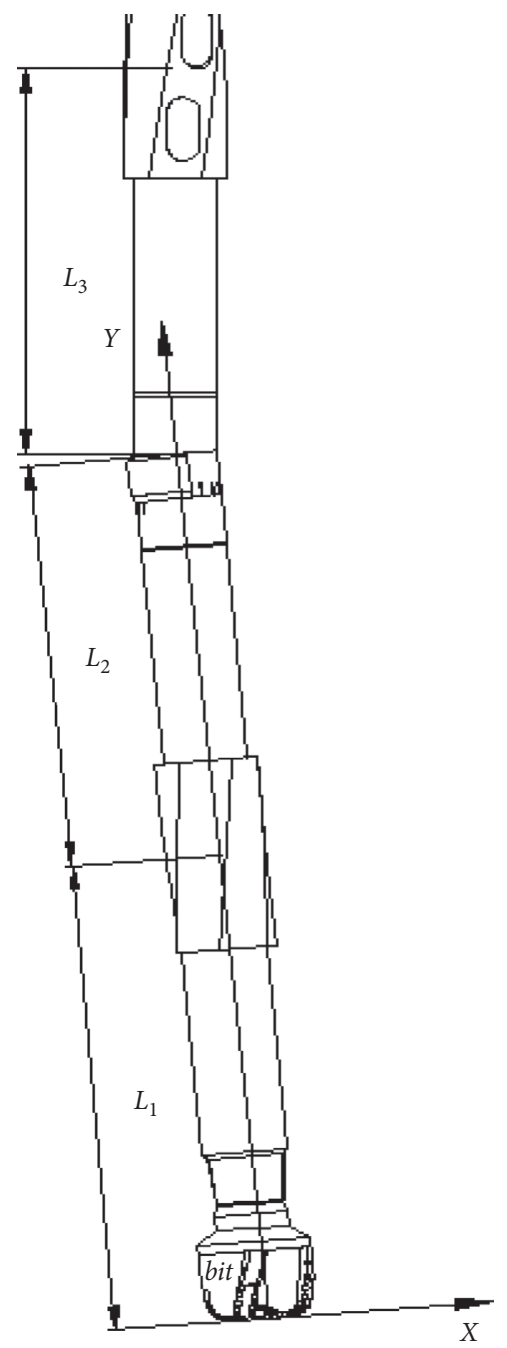

Figure 10: Computational model of compound deflecting BHA.

Table 2 shows comparison between the measured build-up rate and the computational one. When the depth of the well is $1740 \sim 1760.67 \mathrm{~m}$, the measured build-up rate is $6.65 /\left(^{\circ}\right) \cdot(30 \mathrm{~m})^{-1}$, and the computational build-up rate is $6.65 /\left(^{\circ}\right) \cdot(30 \mathrm{~m})^{-1}$; the error between them is $5.354 \%$. Especially in $1777.65 \sim 1788.2 \mathrm{~m}$, the measured build-up rate is $6.80 /\left(^{\circ}\right) \cdot(30 \mathrm{~m})^{-1}$, the computational build-up rate is $6.6791 /\left(^{\circ}\right) \cdot(30 \mathrm{~m})^{-1}$, and the error between them is $1.778 \%$, which is very small. Comparing the measured build-up rate with the computational one, this is little error, which proves the feasibility of the computational model.
4.3. Case Application and Computation. Compound deflecting $\mathrm{BHA}$ is bit + near bit fixed stabilizer + motor with $\mathrm{BAH}+\mathrm{DAS}+$ drill collar + drill pipe. Parameters of a compound BHA are $L_{1}=1.1 \mathrm{~m}, L_{2}=1.2 \mathrm{~m}, L_{3}=4.0 \mathrm{~m}$. The build-up rate needed is $14.0^{\circ} / 30 \mathrm{~m}$, and the radial piston sticking out distance of DAS is: $0,2,4,6$, and $8 \mathrm{~mm}$. Based on the enumeration method, the required angle of bending housing and the telescopic displacement of DAS are acquired as shown in Figure 11.

According to the table above, when the structural angle is $\gamma=1.75^{\circ}$ and the telescopic displacement of DAS is $\delta=2 \mathrm{~mm}$, the demand can be satisfied with little error. Hence, according to the demand of the build-up rate, the structural angle and the telescopic displacement of DAS are acquired based on the enumeration method in order to adjust the build-up rate.

\section{The Evaluation of the DAS Flow Channel Erosion}

5.1. Erosion Model of the Flow Channel. The DAS annular flow channel passes through high-speed fluid when DAS keeps in the normal drilling process, as shown in Figure 12. When well trajectory is required to change in the drilling process, the pressure difference of drilling fluid becomes larger at the inlet of the "funnel" flow regulator passed in the DAS flow channel. Under the action of pressure difference, the piston of DAS is extended out, ultimately achieving deflecting of wellbore. When drilling fluid with a large displacement pass through the DAS flow channel, it is easy to cause erosion at the inlet of the flow passage. Because the drilling fluid contains small solid particles, the high-speed solid-liquid two-phase fluid is likely to cause erosion of the channel wall. The flow regulator easily causes erosive wear due to changes in the shape of the flow channel, so it is necessary to conduct numerical calculation. If the inlet of the flow passage is erosive, the flow rate and pressure difference will be changed. The pressure difference is not directly proportional to piston extension. Finally, the well trajectory control is inaccurate. From the above, it is very necessary to evaluate the erosion of the flow channel.

The calculation model of the DAS flow channel was established according to Figure 13. The nonuniform structure mesh technology was used to mesh. The inlet wall surface, the annulus wall surface, and the outlet wall surface were meshed. Moreover, the inlet wall surface is densely meshed considering the accuracy of the calculation result. As is shown in Figure 14, the model uses tetrahedral mesh, the number of grids is 159,203 , fully implicit multigrid coupling solution technique to make numerical simulation.

In this paper, two computational models are developed: the one is the continuous phase model and the other one is the particle tracking model. The model based on $k-\varepsilon$ fluid dynamics equations and particle motion equation is applied to predict the erosion rate in the flow channel. The instantaneous equations of mass, momentum, and energy conservation and the turbulence model are solved. According to the characteristics of mud-particle two-phase flow in the flow channel, the erosion of the flow regulator is related to the particle impact velocity, impact angle, and so on. Therefore, the erosion model of CFD software is used in this paper [28, 29]. 
TABle 2: Comparison between the measured build-up rate and the computational one.

\begin{tabular}{lccc}
\hline Hole depth $(\mathrm{m})$ & Measured value $\left(\left(^{\circ}\right) \cdot(30 \mathrm{~m})^{-1}\right)$ & Computational value $\left(\left(^{\circ}\right) \cdot(30 \mathrm{~m})^{-1}\right)$ & 7.0061 \\
$1740 \sim 1760.67$ & 6.65 & 6.5477 & 5.354 \\
$1760.67 \sim 1777.27$ & 6.00 & 6.6791 & 9.128 \\
$1777.65 \sim 1788.2$ & 6.80 & 1.778 \\
\hline
\end{tabular}

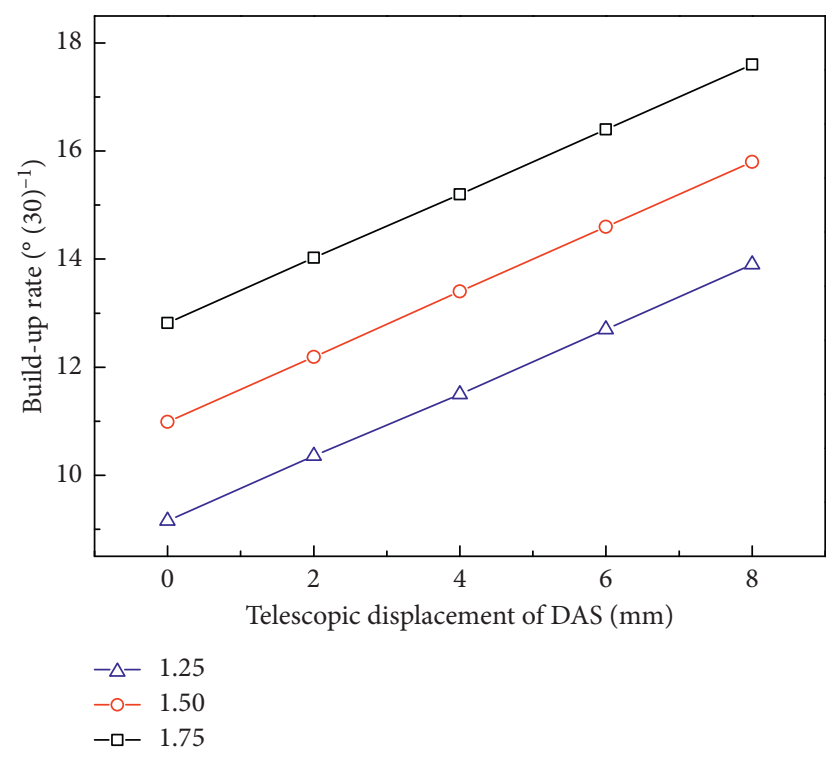

FIgURE 11: Build-up rate computational results of the compound BHA.

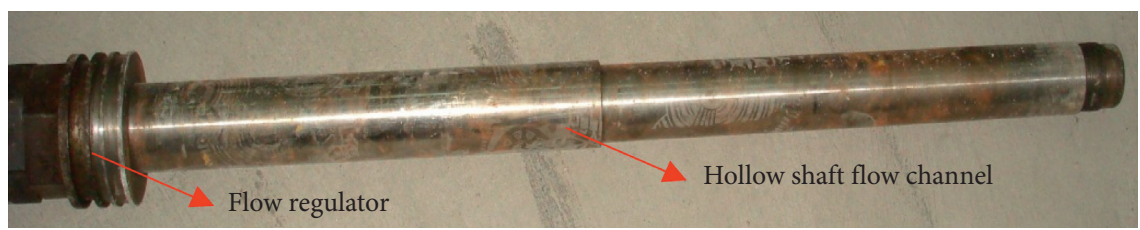

(a)

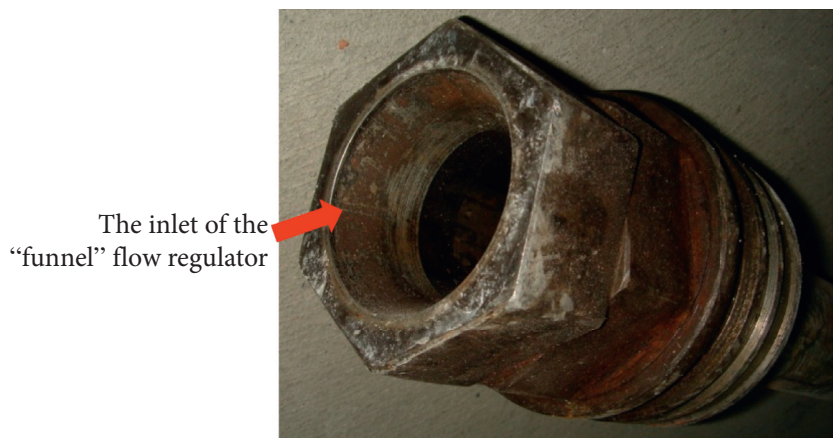

(b)

FIGURE 12: The flow channel of DAS.

5.2. The Evaluation of Erosion under Different Pressure Difference. In order to study the effect of pressure difference on flow channel erosion, the same numerical model as before was used for calculation. When the maximum working differential pressure is $2 \mathrm{MPa}$, the piston of the DAS fully extends. The erosion law of the flow channel is studied, when the pressure difference is changed within the range of $0 \sim 2 \mathrm{MPa}$. The inlet pressure is $0.5 \sim 2 \mathrm{MPa}$, and the outlet pressure is $0 \mathrm{MPa}$. The other boundary conditions are the same as the previous settings. Table 3 shows the erosion rate of the flow channel when the pressure difference is $0.5 \mathrm{MPa}$, $1 \mathrm{MPa}$, and $2 \mathrm{MP}$, respectively. When the pressure difference 


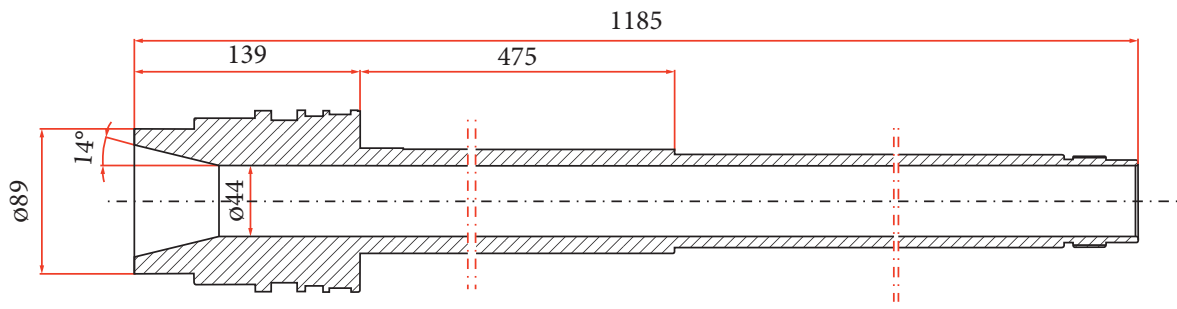

Figure 13: The flow channel diagram.

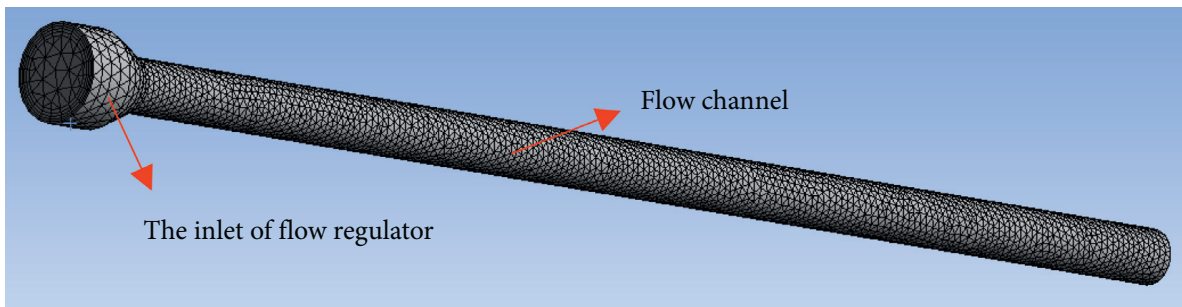

Figure 14: Model mesh.

TABLE 3: Erosion rate at different pressure difference.

\begin{tabular}{lccc}
\hline Pressure difference $(\mathrm{MPa})$ & 0.5 & 1 & 2 \\
\hline Erosion rate $\left(\mathrm{kg} / \mathrm{m}^{2} \mathrm{~s}\right)$ & $6.49 \times 10^{-5}$ & $2.58 \times 10^{-4}$ & $8.03 \times 10^{-4}$ \\
\hline
\end{tabular}

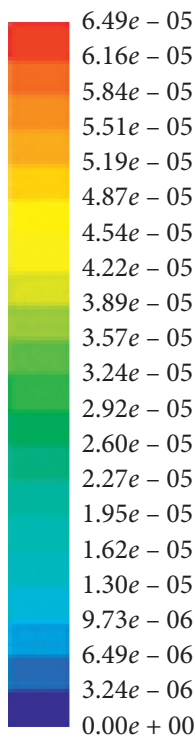

(a)

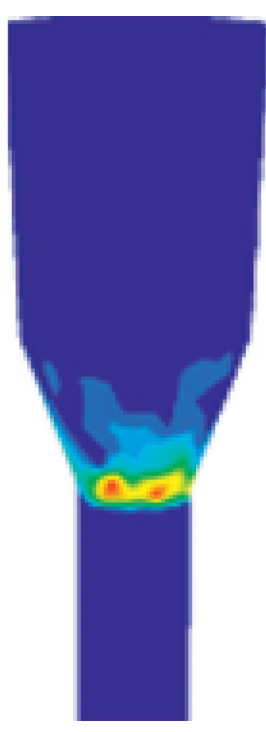

(a)

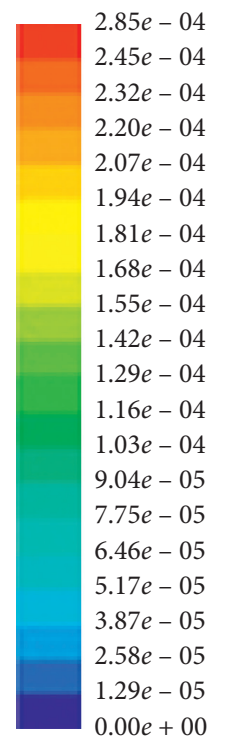

(b)

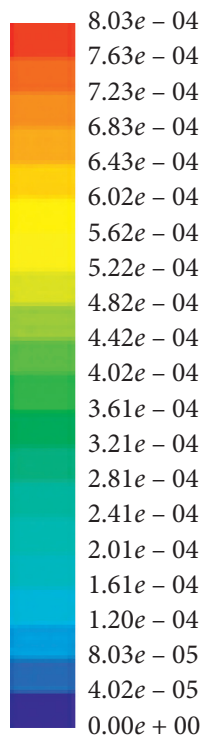

(c)

Figure 15: Erosion rate at different pressure difference. (a) $0.5 \mathrm{MPa}$. (b) $1 \mathrm{MPa}$. (c) $2 \mathrm{MPa}$.

increases from $0.5 \mathrm{MPa}$ to $2 \mathrm{MPa}$, the erosion rate increases from $6.49 \times 10^{-5}$ to $8.03 \times 10^{-4} \mathrm{~kg} / \mathrm{m}^{2} \mathrm{~s}$, and the erosion rate increased by about $91.9 \%$, which shows that the pressure difference has a great influence on the erosion of the flow channel. It can be seen from Figure 15 that the erosion position still mainly occurs at the funnel-shaped flow channel of the flow regulator. It is recommended to use a small differential pressure during the use of the DAS to control the differential pressure as much as possible. In order to make the flow control of the DAS accurately control, the maintenance and replacement of the flow regulator are required.

5.3. The Evaluation of Erosion at Different Flow Rate. The turbulence model and discrete phase model is employed. The inlet flow rate is set from $40 \mathrm{~L} / \mathrm{s}$ to $80 \mathrm{~L} / \mathrm{s}$. The normal and tangential reflectivity of the wall boundary is defined as the 
TABLE 4: Erosion rate at different flow rate.

\begin{tabular}{lccccc}
\hline Flow rate $(\mathrm{L} / \mathrm{s})$ & 40 & 50 & 60 & 70 & 80 \\
\hline Erosion rate $\left(\mathrm{kg} / \mathrm{m}^{2} \mathrm{~s}\right)$ & $5.73 \times 10^{-4}$ & $5.95 \times 10^{-4}$ & $6.76 \times 10^{-4}$ & $7.78 \times 10^{-4}$ & $8.40 \times 10^{-4}$ \\
\hline
\end{tabular}

polynomial function of the particle impact angle. In the erosion model, the impact angle function is defined to describe the ductile damage of the flow channel wall and calculate the flow channel erosion. It can be seen from Table 4 that, as the flow rate increases, the erosion rate of DAS flow channel increases in turn. When the flow rate increases from $40 \mathrm{~L} / \mathrm{s}$ to $80 \mathrm{~L} / \mathrm{s}$, the erosion rate increases by approximately $46.6 \%$. The erosion mainly occurs at the sudden change position of the funnel-shaped flow channel. It can be seen that the erosion is very serious at the abrupt changing place in the funnel-shaped flow channel at the inlet. Therefore, the structure needs to use the erosion-resistant material and has antierosion design. In actual work, the maintenance work of the flow regulator should be done well.

\section{Conclusions}

(1) The compound deflection model of DAS and motor with $\mathrm{BAH}$ is presented. The model is proved to be feasible by field data. It is recommended to continue modifying the model in future application.

(2) The computational formula of wedge's axial moving displacement and piston's radial telescopic displacement of the DAS driven by drilling fluid pressure is presented. Laboratory experiments show that the formula is feasible.

(3) The result shows that the flow rate and pressure difference have a very serious impact on the flow regulator erosion. It is suggested that the flow rate and pressure difference should be controlled, and also flow regulator should be maintained and replaced frequently when in service.

\section{Data Availability}

The data used to support the findings of this study are included within the article.

\section{Conflicts of Interest}

The authors declare that there are no conflicts of interest regarding the publication of this article.

\section{Acknowledgments}

This work was supported by the Natural Science Foundation of China (nos. 51604039 and 51974036) and the Yangtze Fund for Youth Teams of Science and Technology Innovation (no. 2016cqt01).

\section{References}

[1] X. Guo, J. Yang, and X. Zhong, "The status of tight oil drilling technique in North America and its enlightenment to China,"
Oil Drilling \& Production Technology, vol. 36, no. 4, pp. 1-5, 2014.

[2] Spears and Associates Inc., Drilling and Production Outlook, Spears and Associates Inc., Tulsa, OK, USA, 2013.

[3] J. Yang, "Drilling status and prospect of horizontal wells in the United States," International Petroleum Economics, vol. 21, no. 9, pp. 11-15, 2013, in Chinese.

[4] China Industrial Information Network, "China horizontal well drilling + fracturing market size calculation in 2015 [EB/ OL]," August 2013, http://www.chyxx.com/industry/201308/ 215571.html.

[5] R. Wang and F. Yin, "Cost accounting and control of horizontal wells in Sinopec gas field," Commercial Accounting, vol. 10, no. 20, pp. 78-80, 2012.

[6] Z. Wang and D. Gao, "Multi-objective optimization design and control of deviation-correction trajectory with undetermined target," Journal of Natural Gas Science and Engineering, vol. 33, pp. 305-314, 2016.

[7] X. Zhu, S. Liu, J. Jing et al., "KWQ-216 surface controlled downhole variable diameter stabilizer," Oil Drilling \& Production Technology, vol. 24, no. 3, pp. 30-31, 2011.

[8] L. Lawrence, J. Stymiest, and R. Russell, "Steerable motor with integrated adjustable gauge stabiliser provides improved directional drilling performance in the Middle-East," in Proceedings of the SPE Middle East Oil Show, Manama, Bahrain, March 2001.

[9] S. Liu, M. Chen, F. Ding et al., "Working mechanism and mechanical analysis of variable diameter stabilizer for downhole controlled," Science Technology and Engineering, vol. 16, no. 18, pp. 182-187, 2016.

[10] G. Zhang, "Design and calculation of downhole close-loop adjustable stabilizers," China Petroleum Machinery, vol. 32, no. 2, pp. 23-25, 2004.

[11] Y.Su, Research Advance of Control Engineering for under Well, Petroleum Industry Press, Beijing, China, 2001.

[12] J. E. McCormick, G. Osorio, J. Andachi et al., "Adjustable gauge stabilizer and torque and drag reduction tools reduce overall drilling times by at least 20\%: a case study," in Proceedings of the SPE Middle East Oil and Gas Show and Conference, Manama, Bahrain, September 2011.

[13] Y. Chen, J. Fu, T. Ma, A. Tong, Z. Guo, and X. Wang, "Numerical modeling of dynamic behavior and steering ability of a bottom hole assembly with a bent-housing positive displacement motor under rotary drilling conditions," Energies, vol. 11, no. 10, p. 2568, 2018.

[14] H. Liu, T. Ma, P. Chen, X. Wang, and X. Wang, "Mechanical behaviors of bottom hole assembly with bent-housing positive displacement motor under rotary drilling," Arabian Journal for Science and Engineering, vol. 44, no. 6, pp. 6029-6043, 2019.

[15] C. Shi, X. Zhu, J. Deng, and L. Tang, "Analysis of mechanical behavior and hysteresis heat generating mechanism of PDM motor," Journal of Mechanical Science and Technology, vol. 31, no. 3, pp. 1143-1149, 2017.

[16] X. Li, D. Gao, Y. Zhou, and W. Cao, "General approach for the calculation and optimal control of the extended-reach limit in horizontal drilling based on the mud weight window," Journal of Natural Gas Science and Engineering, vol. 35, pp. 964-979, 2016.

[17] X. Chen, H. Fan, B. Guo, D. Gao, H. Wei, and Z. Ye, "Realtime prediction and optimization of drilling performance based on a new mechanical specific energy model," Arabian 
Journal for Science and Engineering, vol. 39, no. 11, pp. 8221-8231, 2014.

[18] L. Shaohu, G. Feng, W. Xianjin, X. Hui, W. Zhen, and Y. Ting, "Theoretical and experimental research of bearing capacity and fatigue life for coiled tubing under internal pressure," Engineering Failure Analysis, vol. 104, no. 10, pp. 1133-1142, 2019.

[19] X. Chen, D. Gao, B. Guo, and Y. Feng, "Real-time optimization of drilling parameters based on mechanical specific energy for rotating drilling with positive displacement motor in the hard formation," Journal of Natural Gas Science and Engineering, vol. 35, pp. 686-694, 2016.

[20] L. Shaohu, X. Hui, G. Feng, J. Qifeng, W. Jiwei, and Y. Ting, "Coiled tubing failure analysis and ultimate bearing capacity under multi-group load," Engineering Failure Analysis, vol. 79, no. 9, pp. 803-811, 2017.

[21] Z. Hou, S. Hu, X. Zhang et al., Mechanics of Materials, Wuhan University of Technology Press, Wuhan, China, 2012.

[22] H. Karlsson and T. Brassfield, "Performance drilling optimization," in Proceedings of the SPE/IADC Drilling Conference, New Orleans, LA, USA, March 1985.

[23] B. R. Hassen and A. J. Macdonald, "Field comparison of medium and long-radius horizontal wells drilled in the same reservoir," in Proceedings of the SPE/IADC Drilling Conference, Houston, TX, USA, February 1990.

[24] X. Liu, S. He, and Ye Zou, "Study on the geometric build angle rate of steerable motor," Acta Petrolei Sinica, vol. 25, no. 6, pp. 83-87, 2004.

[25] R. Brito, E. Pereyra, and C. Sarica, "Effect of well trajectory on liquid removal in horizontal gas wells," Journal of Petroleum Science and Engineering, vol. 156, pp. 1-11, 2017.

[26] Y. Liu and D. Gao, "A nonlinear dynamic model for characterizing downhole motions of drill-string in a deviated well," Journal of Natural Gas Science and Engineering, vol. 38, pp. 466-474, 2017.

[27] X. Liu, "Practical calculation method of geometric deflection rate of guide drilling tool," Natural Gas Industry, vol. 25, no. 11, pp. 50-52, 2005.

[28] S. Liu, H. Zheng, and X. Zhu, "Drill string failure analysis and erosion wear study at key point for gas drilling," Energy Exploration \& Exploitation, vol. 32, no. 3, pp. 553-568, 2014.

[29] X. Zhu, S. Liu, H. Tong, X. Huang, and J. Li, "Experimental and numerical study of drill pipe erosion wear in gas drilling," Engineering Failure Analysis, vol. 26, pp. 370-380, 2012. 